\title{
HEIGHT CHANGES IN THE EPICENTRAL REGION PRECEDING THE JANUARY 17, 1994 NORTHRIDGE EARTHQUAKE
}

By Robert O. Castle, Robert F. Packard, and Laura B. Dinitz

A characterization of the vertical-displacement field

in both space and time during

the period 1978-1989

\section{OPEN-FILE REPORT 00-002}

\section{0}

This report is preliminary and has not been reviewed for conformity with U.S. Geological Survey editorial standards or with the North American Stratigraphic Code. Any use of trade, firm, or product names is for descriptive purposes only and does not imply endorsement by the U.S.

Government

\section{U.S. DEPARTMENT OF THE INTERIOR}

U.S. GEOLOGICAL SURVEY 


\title{
HEIGHT CHANGES IN THE EPICENTRAL REGION PRECEDING THE JANUARY 17, 1994 NORTHRIDGE EARTHQUAKE
}

\author{
By \\ Robert O. Castle, Robert F. Packard, and Laura B. Dinitz
}

\begin{abstract}
Analysis of the results of repeated levelings through the epicentral region of the $\mathrm{M}_{\mathrm{W}} 6.7$, 1994 Northridge earthquake has disclosed the occurrence of differential uplift in this area that preceded the earthquake. Although the distribution of the relevant vertical-control data is somewhat sparse, in both space and time, those data that we have recovered indicate that this uplift exceeded $0.10 \mathrm{~m}$ and peaked $20-25 \mathrm{~km}$ west of the 1994 epicenter. While our data also indicate that this deformational event must have occurred during the period 1978-1989, evidence based on the character and magnitude of misclosures developed from 1987 and 1989 surveys argue that the deformation occurred largely during the period 1987-1989. The preseismic vertical-displacement field that preceded the Northridge earthquake is similar in form and, less certainly, magnitude to that which preceded the $\mathrm{M}_{\mathrm{W}} 6.7,1971$ San Fernando earthquake; other possible, but less significant southern California analogues include the deformational events that preceded the $\mathrm{M}_{\mathrm{W}} 5.3,1973$ Point Mugu and $\mathrm{M}_{\mathrm{W}} 5.9,1987$ Whittier Narrows earthquakes. The small but growing number of recognized aseismic deformational episodes that preceded small to moderate magnitude earthquakes in southern California suggests that the deployment of the dense array of continuously recording GPS receivers planned for southern California can be expected to detect and more accurately describe such events than was heretofore possible. Moreover, if the relation between the duration of these deformational anomalies and the magnitudes of any ensuing earthquakes can be much more clearly established, the near perfect temporal control on position afforded by GPS suggests that we may be on the threshold of a realistic earthquake warning system.
\end{abstract}

\section{Introduction}

Owing to severe funding constraints experienced by a number of local jurisdictions, geodetic control work had virtually ceased in southern California by 1979. It was, in fact, not until the late 1980s, and owing largely to the efforts of the National Geodetic Survey to bring to completion the new North American Vertical Datum, that any significant number of higher order vertical-control surveys were again carried out in this area. Several of these vertical-control lines fell within the subsequently defined epicentral region of the $\mathrm{M}_{\mathrm{W}} 6.7$ Northridge earthquake. Analysis and comparisons of these surveys, though sparsely distributed, against the results of still earlier levelings has disclosed compelling evidence of an intriguing preseismic deformational event, especially when viewed as an indication of what can be expected to emerge with the anticipated installation of a dense array of GPS observatories in southern California, where this array is integrated in turn with interferometric synthetic aperature radar (InSAR) imagery in this region.

While a fairly clearly defined association between a regional deformational event and subsequent earthquake activity has been recognized in southern California (Castle and Bernknopf, 1996), localized preseismic deformational anomalies, such as the one described here, are seemingly rare, whether in southern California or elsewhere. However, their detection has previously depended on the spatial and temporal distribution of those surveys that led to their recognition, surveys not generally deployed with geophysical needs in mind. Thus uncertainty surrounding the frequency of occurrence of these preseismic events, as well, of course, as similar events that show no demonstrable associations with subsequent seismicity, remains unresolved. Discrimination between these separable types of deformational events is especially perplexing and probably will remain so until our data reservoir is vastly enlarged. Nevertheless, current uncertainties should 
gradually diminish with increasing density and accuracy of space-based observations, particularly those based on arrays of continuously recording GPS receivers, such as that now being deployed in southern California that occurred within the epicentral region of the Northridge earthquake between 1978 and 1989--changes that probably occurred over the much shorter interval 1987-1989. We have made no comparisons with pre-1978 work here,

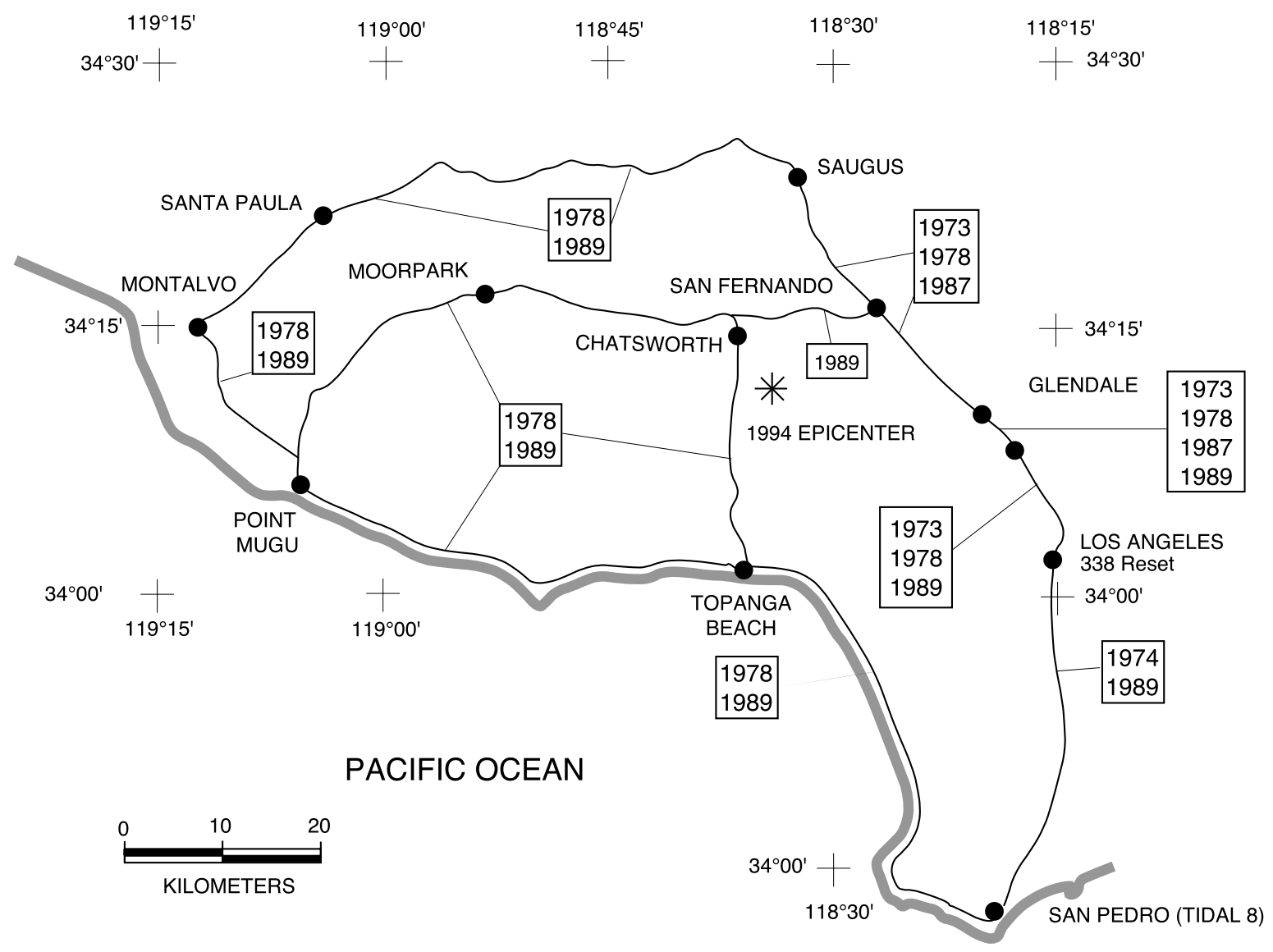

Figure 1. Index map showing routes and dates of levelings used in this report.

or the 1000-station operating network in Japan (Thatcher, 1999).

\section{Vertical-Control Data Utilized in this Report}

The surveys on which this report is based are limited in number (fig. 1). They are, nonetheless, of sufficient density that we have been able to reconstruct those height changes other than for demonstration purposes, chiefly because this area is known to have sustained major regional deformation sometime during the interval 1974-1978 (Castle and Gilmore, 1992; Castle and Bernknopf, 1996). All of the elevations, and hence all of the elevation or height changes, have been reconstructed with respect to bench mark Tidal 8, San Pedro. This control point traditionally has been utilized for these purposes because of its proximity to the San Pedro tide station. Because sea-level has 
been falling at San Pedro relative to other California tide stations (Hicks and Shofnos, 1965; Hicks and Crosby, 1974), height changes referred to Tidal 8 tend to bias these changes against the recognition of uplift and towards the recognition of subsidence.

Measurement Accuracy. All of the utilized levelings meet either class I or class II firstorder standards. All have been corrected for rod error, thermal expansion of the rods, and instrument collimation error. Staff settlement, which can produce a commonly overlooked source of systematic error, is tightly controlled in first-order work by requiring that the direction of running be both regularly and frequently reversed. The modeled refraction corrections of the National Geodetic Survey have not been incorporated in any of the lines utilized in our analysis simply because they tend to degrade the survey data (Castle and others, 1985; Mark and others, 1987; Castle and Gilmore, 1992; Castle and others, 1994)--see below. While a degree of systematic error surely has crept into these measurements, because those corrections that we have accepted are based on the most modern (late 20th-century) calibration techniques, the known range of thermal expansion values for invar identified with particular types of rods, and very restrictive field procedures, whatever systematic error remains no more than competes with, and, in the general case, probably is a good deal less than the estimated random error.

The standard deviation $(\sigma)$ in the measured elevation difference between any two marks (virtually interchangeable here with random error) is adequately described by an expression of the form $\alpha \mathrm{L}^{1 / 2}$, where $\alpha$ is in units of $\mathrm{mm} / \mathrm{km}^{1 / 2}$ and $\mathrm{L}$ is the distance in kilometers between the indicated marks. The 1978 base line leveling was double run to current firstorder, class I standards, where the standard deviation has been derived through statistical examination of the section closures. The standard deviations for the five 1978 lines utilized here range between \pm 0.66 and $\pm 0.73 \mathrm{~mm}$ for a $1-\mathrm{km}$ section (the $\alpha$ term in our standard deviation expression), for an average of \pm 0.70 $\mathrm{mm}$. The subsequent 1987 and 1989 levelings met first-order, class II standards, but all were single run; the equipment and procedures were otherwise identical to those currently in force for double-run first-order leveling (Federal Geodetic Control Committee, 1984, p. 3.6-3.8). Thus acceptance of the square root rule indicates that the standard deviation for a 1$\mathrm{km}$ section obtained from the 1987 and 1989 leveling should be about $0.7 \times \sqrt{2}$ or approximately $1.00 \mathrm{~mm}$. Accordingly, an average value for $\alpha$ based on a comparision of the results of the later 1987 and 1989 levelings against those of the 1978 work would be about $1.22 \mathrm{~mm} / \mathrm{km}^{1 / 2}$. Because the greatest length of any of these levelings referred to Tidal 8 is about $220 \mathrm{~km}$, the estimated random error associated with the height changes reported here reaches a maximum of about $18 \mathrm{~mm}$.

In spite of the rigorous standards and procedures that have been adopted in order to minimize systematic error in any geodetic leveling, particularly those embraced during the last three or four decades, a good deal of doubt still attaches to the accuracy of geodetic leveling relative to the described signals. This doubt stems largely from the conviction on the part of a number of geophysicists that significant height (rod)- or slope (refraction)dependent error (at or above various or virtually all the signals described here and elsewhere) has seriously contaminated the data (Jackson and others, 1980; Reilinger and Brown, 1981; Strange, 1981; Holdahl, 1982; Stein and others, 1986; and Geller, 1997). Disbelief in the accuracy of the measurement system attributable to disagreement between heights or height changes obtained from steric leveling or relative changes in sea level along selected coasts is thought to have largely dissipated (Castle and Elliott, 1982). Similarly, significant residual rod error (above that accounted for through normal calibration procedures) has rarely, if at all, been cited in recent years as a significant contaminant in geodetic leveling (see, for example, Mark and others, 1981; Stein, 1981; Craymer and others, 1995). This is not the case, however, with respect to the so-called unequal-refraction error (URE). While, as we note above, such evidence as we have before us indicates that the URE simply does not accumulate to values that even begin to match the estimated random error-owing to both the procedural constraints and observer experience identified with any geodetic leveling--we have examined the 
effect of the modeled refraction corrections of the National Geodetic Survey on two lines utilized here that should be especially vulnerable to any URE. Both of these lines are characterized by relatively shallow slopes over significant height differences $(300 \mathrm{~m}$ over $65 \mathrm{~km}$ in the first case and $370 \mathrm{~m}$ over $55 \mathrm{~km}$ in the second case). The magnitudes of the modeled refraction corrections applied to both of the comparative levelings are such that they increase the height changes along one of these lines by a maximum of about $4 \mathrm{~mm}$ and decrease the height changes along the other by about $2 \mathrm{~mm}$. Accordingly, even though we have not incorporated refraction corrections here, had we chosen to do so it would have had little impact on this analysis.

Although, as we imply in the preceding paragraph, geodetic leveling is now thought to be about as accurate as it was believed to be prior to the late 1970 's, this conclusion is qualified by the fact that the worst systematic error ever recognized in any terrestrially based geodetic measurement system could have compromised our analysis. Specifically, the 1978 leveling was based in part on the utilization of a particular automatic level, the Zeiss Ni l, that was subject to a potentially large magnetic deflection error. This error is design dependent, instrument specific, azimuth dependent, and time dependent, such that hindcast corrections could be expected to be no more than approximate. Nevertheless, following the recognition of this error in the early 1980's, the National Geodetic Survey developed an empirical correction (Holdahl and others, 1987) that successfully diminished or even removed this error in varying degree. The only 1978 line used here that incorporates any $\mathrm{Ni} 1$ leveling is the one that runs along the coast between Tidal 8 and Montalvo (fig. 1). The difference between the empirically corrected and uncorrected levelings between Tidal 8 and Topanga Beach is $4 \mathrm{~mm}$; that between Tidal 8 and Montalvo is $7 \mathrm{~mm}$. Thus, while it would have made little difference whether we did or did not incorporate this correction, both the generalized azimuth of this line and our own experience with the NGS empirical corrections indicate that utilization of this correction is probably the safest procedure to follow. We have tested the effectiveness of this correction along the coastal route by backing into our Los Angeles starting mark, 338 Reset, via 1978 leveling through Montalvo and Saugus (fig. 1). This procedure produces a height for this mark of $103.4210 \mathrm{~m}, \mathrm{a}$ value that falls within millimeters of the 1974 and 1989 heights for 338 Reset (103.4192 $\mathrm{m}$ and $103.4171 \mathrm{~m}$, respectively)--an admittedly fallible, but certainly supportive indication of the accuracy of the magnetically corrected 1978 leveling. 1978 Ni 1 leveling was also carried out between Tidal 8 and 338 Reset. However, based on a comparison between the empirically corrected and uncorrected values over this reach, the magnetic error accumulated to at least $50 \mathrm{~mm}$; because the resulting, corrected height falls several centimeters below the 1974 and 1989 heights for this mark, it probably underestimates the actual error. Thus, the 1978 survey between Tidal 8 and Los Angeles has been rejected for use in our analysis.

Finally, survey blunders or "busts" constitute a separate category of leveling error and are considered here under a separate heading (see "Results").

\section{Results}

The chief results of our analysis are summarized as profiles of height changes, together with their corresponding terrain profiles (fig. 2). Comparison of these height changes against terrain provides a qualified procedure for searching for either height- or slope-dependent error (although obviously not for magnetic error nor staff settlement). Even though none of the profiles start at the San Pedro tide station, all of the height changes have been reconstructed with respect to bench mark Tidal 8 as fixed in height. The 1978-1989 height change shown at San Fernando (P 1296) (fig. 2A) is based on a 1989 tie between Chatsworth (C 1452) and San Fernando that does not relevel any earlier (1978 or later) survey over this route. Accordingly, the 1989 tie between C 1452 and P 1296 is based on the assumptions that: (1) the orthometric correction applicable to the leveling between Chatsworth and San Fernando can be taken as zero; and (2) the difference in the orthometric corrections in the levelings northward into C 1452 and P 1296 

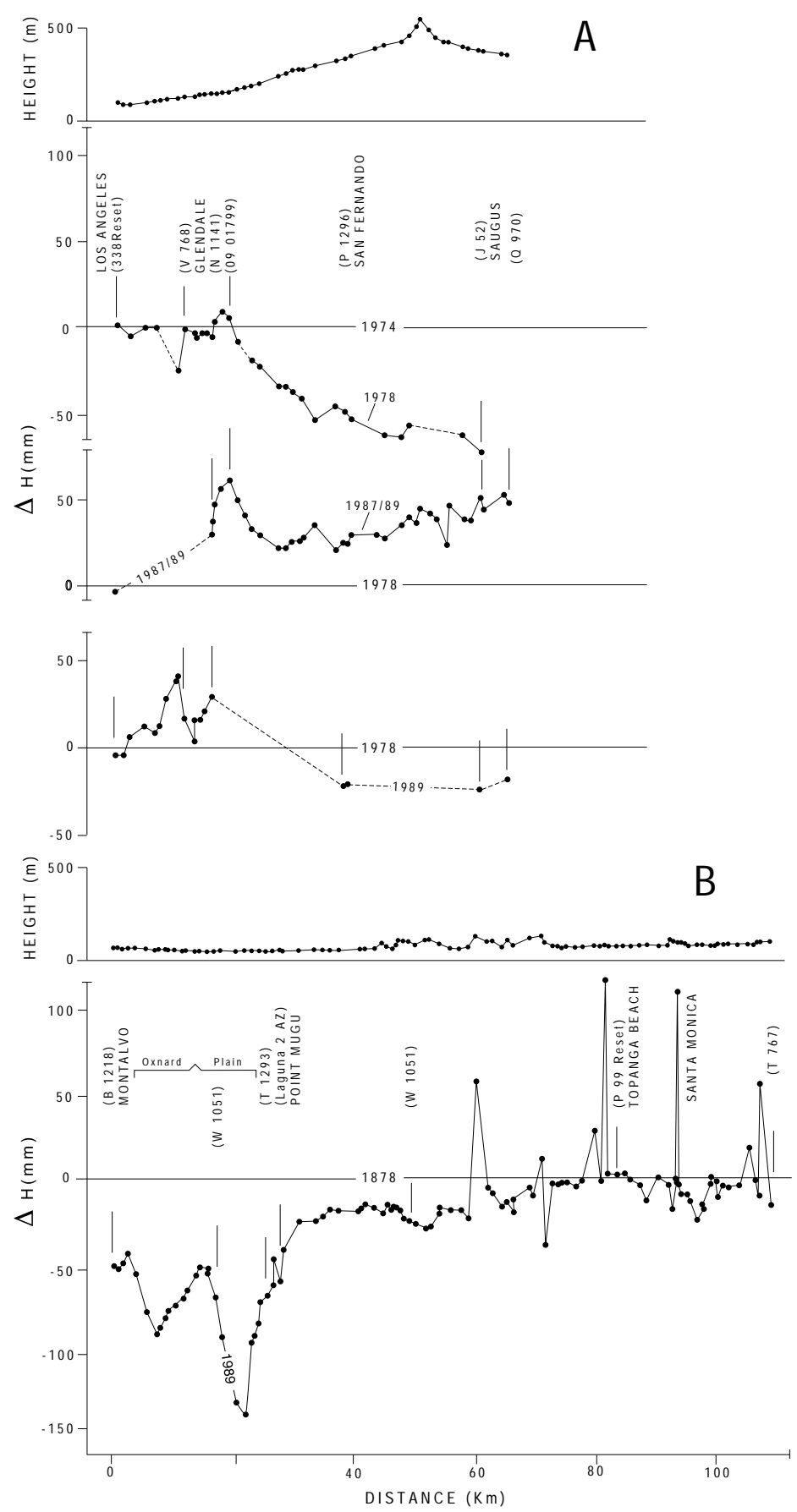

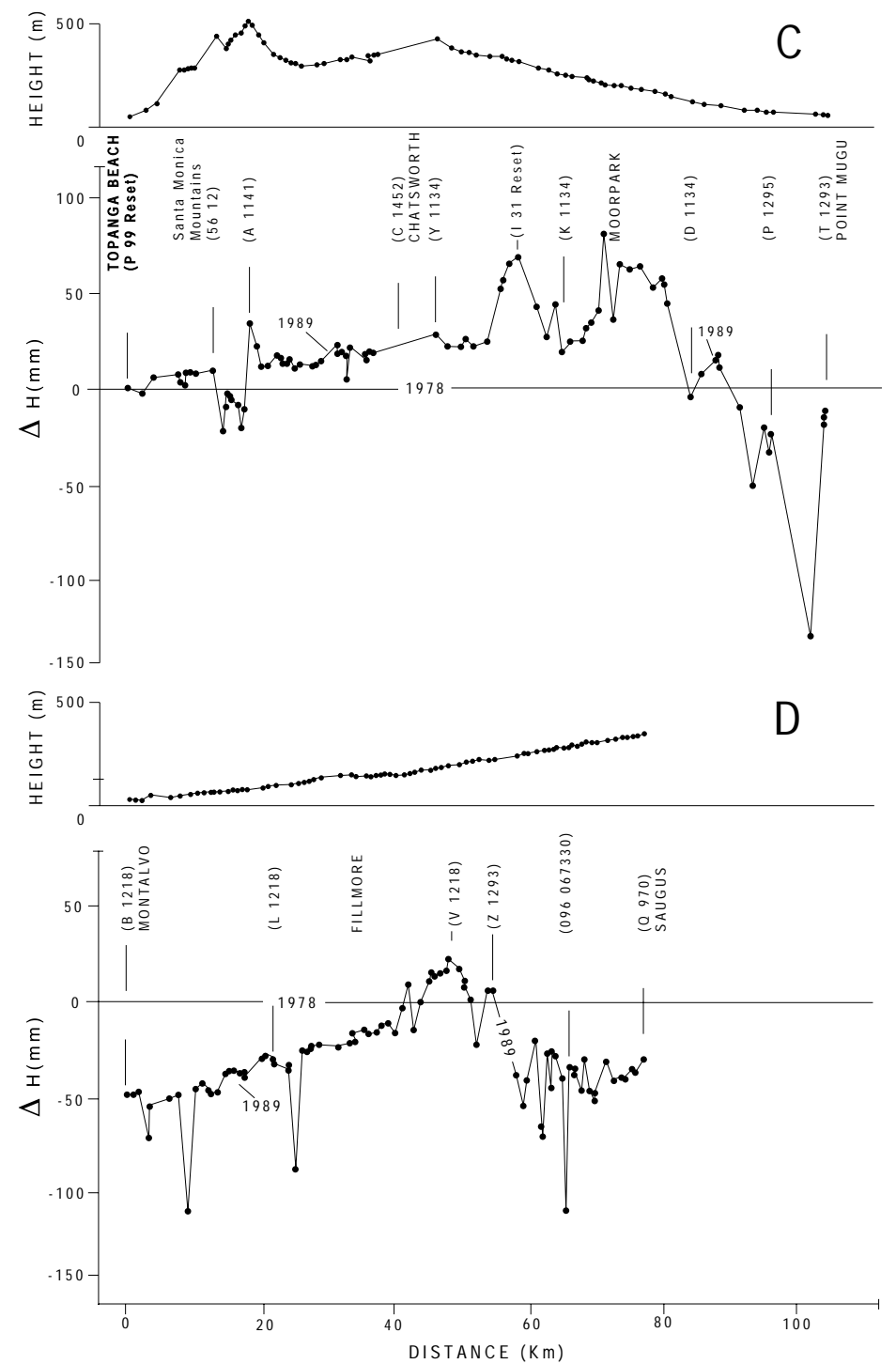

Figure 2. Profiles showing terrain and height changes $(\Delta \mathrm{h})$ with respect to bench mark Tidal 8 along four lines within or adjacent to the epicentral region of the 1994 Northridge earthquake. Height-change segments devoid of comparative heights shown by dotted line. (A) Los Angeles to Saugus route; the 1974-1978 comparison provides a small sample of the very broadly defined regional deformation sustained over much of southern California during this interval. (B) Santa Monica to Montalvo route. (C) Topanga Beach to Point Mugu via Chatsworth route. (D) Montalvo to Saugus route. 
from Tidal 8 is negligible. Owing to the roughly comparable heights identified with these marks ( 316 and $380 \mathrm{~m}$ ) and the very short reach $(\sim 25 \mathrm{~km})$ and approximately east-west trend between them, we view these as conservative assumptions--assumptions supported by the generally small orthometric closures around all of the circuits within the epicentral region (Burford and Gilmore, 1984, p. 2-5)

Examination of the profiled
comparisons discloses two significant
discrepancies in the represented height changes. The most obvious is that obtained by comparing the height changes at Q 970, near Saugus, derived from the results of levelings eastward through Fillmore to Saugus (fig. 2D), against those extending northwestward out of Los Angeles (fig. 2A). The 1987/89 Los AngelesSaugus survey was constructed through joining the results of 1987 leveling between Glendale and Saugus with a 1989 line extending northward from Tidal 8 to Glendale ( fig. 1). Nonetheless, because the 1987 elevation differences over the $\sim 3-4-\mathrm{km}$ reach between $\mathrm{V}$ 768 and N 1141 (fig. 2A) are very nearly an exact overlay of those based on 1989 leveling (an end-to-end difference of $0 \mathrm{~mm}$ with a maximum departure from 0 --midway along this comparative reach--of only $2 \mathrm{~mm}$ ), a reasonable case can be made that even if the 1987 leveling had begun at Tidal 8, the stability of 338 Reset and uplift at Q 970 would have been about the same as that shown here (fig. 2A). The height change at Q 970 based on surveys northward from Tidal 8 along the coast and thence eastward from Montalvo, indicates that Q 970 subsided $29 \mathrm{~mm}$ during the period 1978-1989 (fig. 2D), whereas the 1978-1987/89 height change obtained from levelings northwestward from Los Angeles indicates that Q 970 rose by 47 $\mathrm{mm}$. The second discrepancy of $55 \mathrm{~mm}$ emerges from the results of levelings along the coast into bench mark T 1293 (fig. 2B) and those over the route between Topanga Beach, via Chatsworth and Moorpark, into this same mark (fig. 2C). While no two sets of levelings are apt to produce exactly the same height changes at any indicated junction point, differences in height changes of the order of millimeters or, conceivably, a centimeter or two are more reasonably anticipated over an area as limited as that with which we are dealing here.

If the described discrepancies are well above those expected with first-order work, we are left with providing a reasonable explanation for these discrepancies. Errors in the reconstruction of the observed elevations with respect to Tidal 8 leap to mind. We have reexamined these reconstructions with considerable care and have found no basis to seize upon this explanation. The second possible explanation is measurement error, especially systematic error. However, as we show above, neither rod nor refraction error can reasonably explain the discrepancies in the height changes at these two points. Systematic accumulation of a magnetic deflection error well above the empirically hindcast error in the 1978 leveling along the coast is clearly a possibility (see, for example, Castle and Gilmore, 1994). Nevertheless, because the surveys between Topanga Beach and Point Mugu follow a line that is nearly orthogonal to magnetic north, where any magnetic error would have to accumulate in order to explain the second discrepancy in particular, this possibility is especially unlikely. Random error seems an equally unlikely explanation for either of these discrepancies. The estimated random error in the signal at Q 970, based on repeated levelings over the two separate routes into this mark out of Tidal 8 , is about $\pm 22 \mathrm{~mm}$. The estimated random error in the signal at $\mathrm{T}$ 1293, based on repeated levelings over the two alternative routes into this mark, again with respect to Tidal 8 , is about $\pm 20 \mathrm{~mm}$

If neither systematic nor random error afford particularly satisfactory explanations for the discrepancies at Q 970 and T 1293, there is always the possibility that these discrepancies are attributable to simple blunders or "busts" in the levelings leading into these two marks. Or, as Schomaker and Berry (1981, p. 3.5) correctly caution, "no unit is so experienced [in geodetic leveling] that the work performed by the group can be automatically considered free of blunders."

Blunders are divided into "random" and "systematic" categories by Schomaker and Berry (1981, p. 3.6). Random blunders include: 
(1) mistakes in reading or recording scale values; (2) observing the rods in the wrong order; (3) improper placement or leveling of the instrument; (4) gross movement of the instrument or turning points during the setups ; (5) improper placement or plumbing of the rods; and (6) gross movement of the forward point between setups. Schomaker and Berry note that the first four of their listed random blunders may be detected and eliminated by using double-scale rods in conjunction with a parallel plate (optical) micrometer and computer recording equipment, as was done in connection with both the 1987 and 1989 leveling utilized here. The blunders included under items 5 and 6 can be detected in hindsight only by comparing repeated levelings over the same line. Blunders of this type are disclosed as offsets that carry through the remainder of the compared line segment from the point of the blundered observation. Because the repeated levelings out of Tidal 8 into both Los Angeles and Topanga Beach close within millimeters (fig. 2), the likelihood of any blunders over these line segments can be dismissed. Similarly, comparisons of the repeated levelings over the several profiles examined here (fig. 2) disclose no detectable offsets. Spikes or other indications of displacement that "come back on datum" are clearly not in the category of perpetuated offsets along the compared lines.

"Systematic" blunders are, in effect, one-time blunders that produce systematic effects. They are attributable primarily or entirely to procedural failures and include such things as improperly performed collimation or compensation checks. Systematic blunders are not easily detected, although their effects may be minimized by still other procedural constraints. Barring collective incompetence, systematic blunders are probably rare, since they are apt to be detected by more than one member of the survey party.

The misclosures around the two circuits defined by the 1987 and 1989 levelings (fig. 3) could be interpreted as evidence of survey blunders. The misclosure around circuit $\mathrm{A}$ is only slightly below limits for first-order, class 2 leveling (90.4 mm allowed for a $327-\mathrm{km}$ circuit) and that around circuit $B$ again pushes the allowed limit of $60.6 \mathrm{~mm}$ over a $147-\mathrm{km}$ circuit. Indeed, the existence of survey errors (blunders) can always be asserted without the possibility of direct disproof. Nevertheless, because the instrumental and procedural requirements built into both the 1987 and 1989 levelings are so restrictive, and because independent evidence of their occurrence is otherwise unrecognized, blunders are considered very unlikey explanations for either of these two misclosures.

There is, however, an alternative explanation for both the cited discrepancies and the indicated misclosures (fig. 3) that does not fall back on survey error. Specifically, while geodetic leveling is an inherently accurate measurement system, its value is compromised by one significant consideration: it is time consumptive. Should any movement occur along the survey route during the course of otherwise flawless leveling, it would be expressed as a misclosure proportional to the magnitude of the postulated movement.

Accepting the plausibility of intrasurvey movement during any given leveling, we can easily explain the discrepancy at Q 970 as deformation (differential subsidence) northward from Glendale during the the two-year interval 1987-1989. We can also, but much less easily, explain the discrepancy at T 1293 in much the same way. That is, there was a three- to four-week delay (late spring to early summer) between the initiation of leveling at T 1293 that extended eastward through Moorpark and Chatsworth, and subsequent leveling into this mark along the coast. In other words, we argue here that during this very short interval T 1293 subsided about $50 \mathrm{~mm}$. Moreover, accepting this explanation, it is very unlikely that this is an expression of compaction-induced subsidence, since the compaction rate at this mark would have to have exceeded the previously recognized maximum rate in the center of the Oxnard Plain (Castle and others, 1977, p. 222) by a factor of more than 3. While any suggestion that aseismic, tectonically induced vertical displacements operate with this rapidity invites immediate skepticism, there is growing evidence that such displacements do occur, and, indeed, that the verticaldisplacement field in southern California is both sharply episodic and oscillatory (see, for 


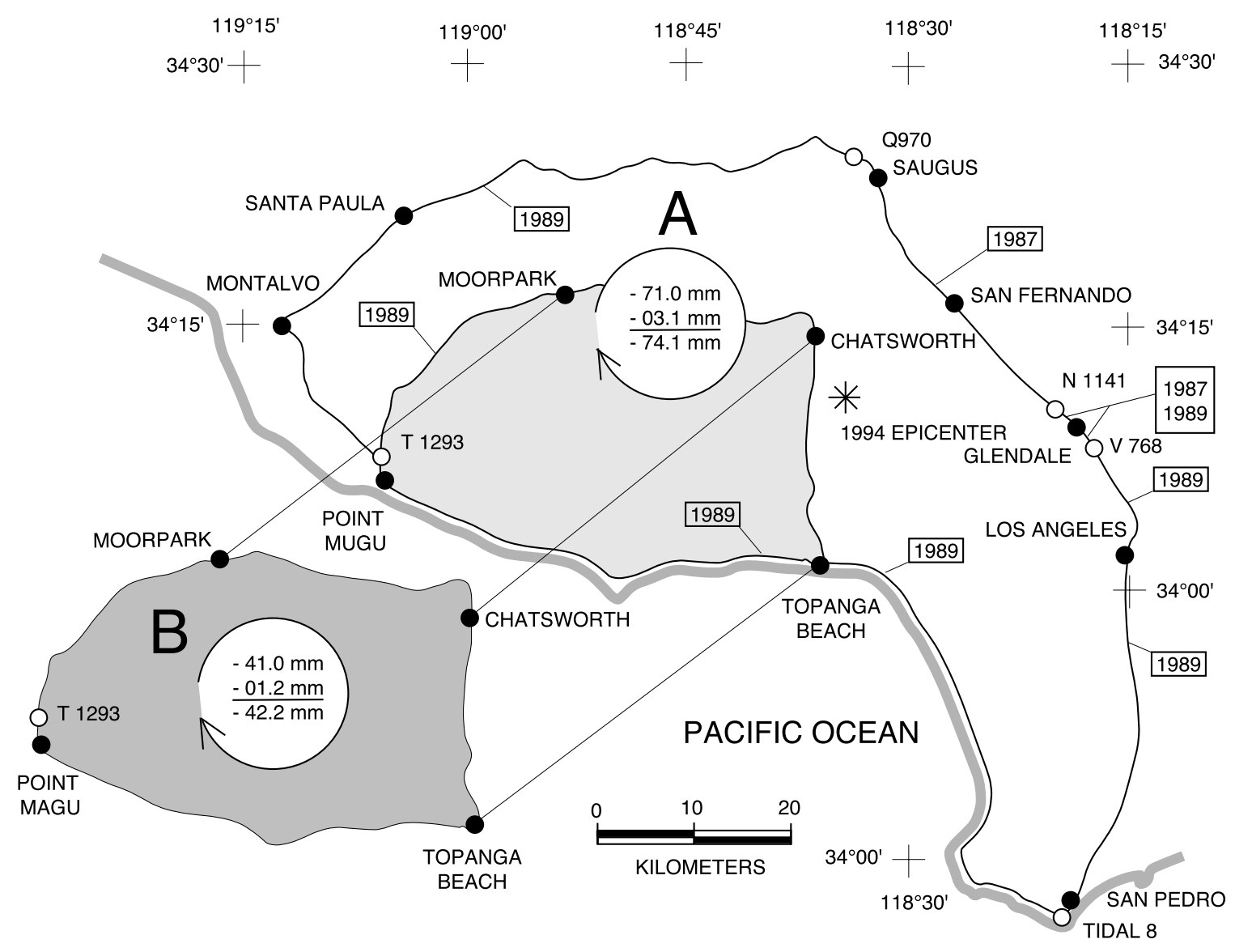

Figure 3. Misclosures around selected circuits based on 1987/89 and 1989 levelings within or adjacent to the epicentral region of the1994 Northridge earthquake. Upper figure identified with each misclosure is summation of corrected observed-elevation differences around the circuit; figure on second line is summation of orthometric corrections around the same circuit, where orthometric corrections are based on observed gravity. The sum of the two preceding values, below the solid line, represents the orthometrically corrected misclosure around the indicated circuit A. Combined 1987 and 1989 levelings (see Figure 1). B. 1989 levelings only.

example, Castle and Gilmore, 1992). By way of illustration, the first of the two major increments of uplift associated with the growth of the southern California uplift, about $0.18 \mathrm{~m}$, had to have occurred sometime between the late spring and early autumn months of 1961 (Castle and others, 1984).

The likelihood that the two described discrepancies are the products of intrasurvey movement, where the considered survey in one case extended over a two-year period and that in the second over no more than about a month, is supported by the misclosures around the two critical circuits (fig. 3). The misclosure (fig.
3A) that necessarily involves any vertical displacment at Q 970 during the interval 19871989 sums clockwise around this circuit to -74.1 $\mathrm{mm}$, a figure that is consistent in sense and magnitude with subsidence of $76 \mathrm{~mm}$ at this mark, as measured with respect to Tidal 8, during the 1978-1987/89 interval. This consistency is not a tautology, since the -76-mm figure is derivative from a comparison between the results of two successive surveys, whereas the $-74.1-\mathrm{mm}$ value depends on the misclosure obtained from a single, albeit discontinuous survey. The contrarian view, and one that should not be dismissed out of hand, argues that the signal (the 76-mm subsidence) is simply an 
expression of survey error that is virtually demanded by the misclosure (fig. 3A). If this argument is pursued, however, it would also require that over 97 percent of the defining error (the signal equivalent) be attributed to the later leveling--certainly a possibility, but one that challenges believability. If we reject the contrarian view, the $1987 / 89$ misclosure (fig. 3A) testifies to both: (1) the high probability that the deformation described here occurred largely during the period 19871989; and (2) a high level of accuracy identified with the appropriately corrected 1978 leveling--against which the subsequent 1989 and 1987/89 levelings produced subsidence at Q 970 that almost precisely matches that deduced from the misclosure (fig. 3A). While this misclosure supports the accuracy of the 1978 leveling, it provides no independent support for the accuracy of the subsequent levelings, since, for example, any increase in the value of the 1987 observed elevation difference between Glendale and Saugus would enlarge both the comparative-based subsidence and the misclosure by exactly the same amount. The same, but much less definitive argument can be developed from the misclosure given in figure 3B. That is, this misclosure again accounts in both sense and magnitude for a large fraction of the subsidence $(42.2 \mathrm{~mm}$ versus 55 $\mathrm{mm}$ ) observed at bench mark T 1293.

The profiled height changes (fig. 2) can be more readily grasped when displayed in map form (fig. 4). In transferring the data from profiled to contoured height changes, we have deliberately ignored the profiled spikes as nothing more than indications of bench mark disturbance. Similarly, we have disregarded zones of compaction-induced subsidence, ranging upward from small pockets that straddle no more than a bench mark or two to domains as large as that in the Glendale area (California State Water Rights Board, 1962, pl. 31) or that astride the Oxnard Plain (fig. 2). Thus the map presentation (fig. 4) constitutes a relatively generalized characterization of height changes, a characterization that clearly involves an element of subjectivity. For example, a feature that occurs along the south flank of the Santa Monica Mountains, between bench marks 5612 and A 1141 (fig. 2C), that could easily have been interpreted as a tectonic signal is, in fact, simply an expression of apparently continuing or reactivated movement along the west side of a large landslide (Yerkes and Campbell, 1980). In any case, were we to attempt to show all of the recognized height changes--regardless of origin--on the map, it would certainly diminish, if not destroy, the coherence of the map. While the accuracy of the contoured height changes is, among other things, proportional to the distance of a given point from the indicated survey route (fig. 1), the contours are, nonetheless, fairly tightly constrained. Accordingly, what finally emerges on this map (fig. 4) is the closest representation that the data permit of the 1978-1989 (or, more likely, 1987-1989) verticaldisplacement field that can be attributed to apparently aseismic tectonic deformation within the epicentral region of the subsequently defined Northridge earthquake.

Several points are illustrated on the map (fig. 4) that are certainly more evident than could be gleaned from a casual examination of the profiled height changes. For example, the contoured height changes spread out southeastward from their high in the Moorpark-Chatsworth area, whereas they tend to bunch up along the north flank of the uplift. This north-south asymmetry athwart the uplift, moreover, is a virtually inescapable consequence of however the profiled data might be contoured.

\section{Interpretation}

Accepting the subjectivity in transferring the data from the several profiles (fig. 2) to the map showing contoured height changes (fig. 4), it is difficult to reject the conclusion that the indicated verticaldisplacement field is somehow related to the crustal disturbance identified with the 1994 earthquake. The spatial association with the epicentral region is remarkably well defined, even though the modeled coseismic uplift given by Hodgkinson and others, (1996, accompanying map) peaks some $20-25 \mathrm{~km}$ east of the zone of maximum uplift shown in figure 4 . The temporal isolation of the deformational event shown here (fig. 4) is still uncertain, but as we indicate above, while it clearly fell within the interval 1978-1989, the evidence disclosed by the misclosures, even though unique, indicates 
that all or nearly all of the relative uplift occurred within a much shorter period-namely, sometime betweeen 1987 and 1989 or roughly 5-7 years before the earthquake. to the modeled uplift astride deep slip on a thrust fault (see, for example, Savage and Hastie, 1966 or Freund and Barnett, 1976). Thus a possible explanation for the observed uplift

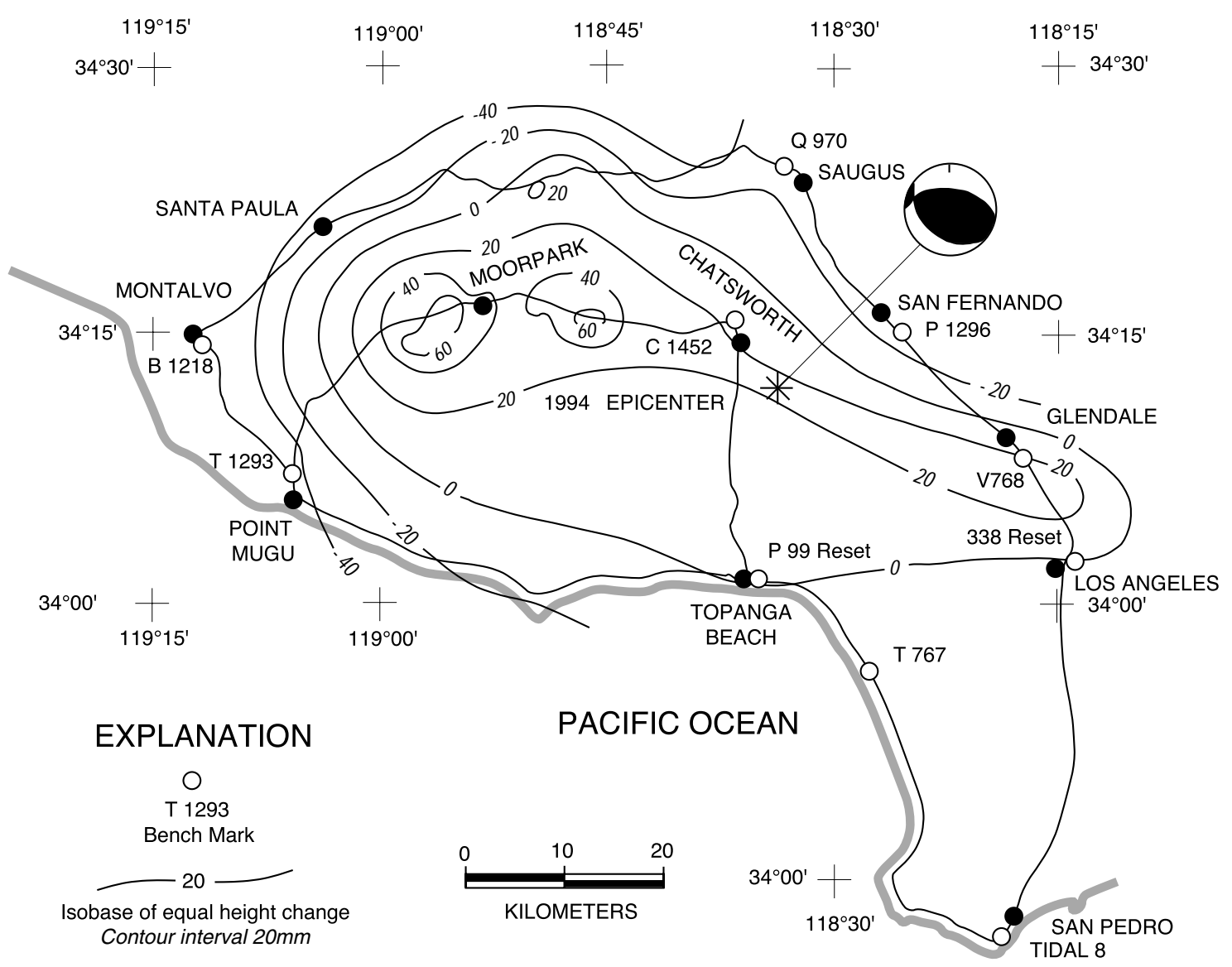

Figure 4. Map showing 1994 epicenter, focal mechanism, and contoured height changes with respect to bench mark Tidal 8 within the epicentral region of the Northridge earthquake. Focal mechanism from Thio and Kanamori (1996).

Based on both the focal mechanism for the main shock (Thio and Kanamori, 1996) and the aftershock distribution (Hauksson and others, 1995), the seismogenic fault that produced the 1994 earthquake dips to the south at an angle of about $42^{\circ}$. Had the displacement on this fault propagated to the surface, it would have broken ground along the north flank of the uplift, precisely where the preseismic contours tend to steepen (fig. 4). The resultant deformational asymmetry through the waist of the uplift (fig. 4) is similar in form is preseismic slip on a down-dip extension of the south-dipping fault that produced the main shock.

Comparisons with at least two other southern California examples of localized aseismic deformation, followed by earthquakes of small to moderate magnitude, lend credibility to the interpretation of this event (fig. 4) as a preseismic (effectively, a precursive) event and offers some support for its probable origin. The best example of localized 
aseismic deformation recognized in southern California, and reasonably interpreted as precursive deformation, is that which preceded the $M_{\mathrm{W}} 6.7$ San Fernando earthquake of 1971 (Castle and others, 1974). The San Fernando example is more revealing in terms of the temporal nature of the preseismic deformation, but somewhat less spatially constrained, since it depended on repeated levelings along what were effectively only two lines. Two well defined episodes of localized uplift were recognized, both of which peaked as close to the subsequently recognized epicenter as the levelings permitted. The first occurred between 1964 and and 1965 (see, also, Castle and others, 1984, pl. 8A) and the second occurred during the period 1968-1969. Thus this deformation occupied a time frame preceding the earthquake of about the same duration as that which preceded the Northridge shock. There may have been a still earlier event, one which occurred sometime between 1961 and 1964. However, there is a good deal of uncertainty as to whether this event should be associated with activity on the adjacent Santa Susana fault, rather than the fault that produced the 1971 San Fernando earthquake. The spatial dimensions of the pre-San Fernando events were about the same or slightly less than those associated with the Northridge deformational event--although that in the east-west direction can only be inferred from its extent eastward from Saugus and a presumption of rough symmetry. A significant and possibly pertinent difference in the earthquakes themselves, however, is in their depths. While the Northridge was identified with a relatively deep focus of about $18.4 \mathrm{~km}$, the main shock of the San Fernando earthquake occurred at less than half that depth--about $8.4 \mathrm{~km}$.

A second, and certainly less definitive example of aseismic uplift preceding a southern California earthquake, was that which preceded the $\mathrm{M}_{\mathrm{W}} 5.3$ Point Mugu shock of February 1973 (Castle and others, 1977). The seismogenic fault that produced this earthquake strikes about $\mathrm{N} 80^{\circ} \mathrm{E}$ and probably dips about $36^{\circ}$ to the north (Stierman and Ellsworth, 1976). The nodal plane solution, moreover, suggests oblique slip, a possibly significant consideration in the present context. The horizontal dimensions of the preseismic uplift at Point Mugu are known in only one direction, $\sim \mathrm{WNW}$, over which it extended no more than about $25 \mathrm{~km}$. Measured uplift with respect to a control point west of Ventura exceeded $30 \mathrm{~mm}$ and persisted through at least the period 1971-1973 or, conceivably, the much longer period 1969-1973. Thus the duration of this anomaly could have been as long as 3.5 or as short as $1.0+$ years. While the measured amplitude of the uplift was only about $30 \mathrm{~mm}$, allowance for likely compaction-induced subsidence suggests that the tectonic signal was closer to $40-50 \mathrm{~mm}$. Although both the preseismic and coseismic uplift peaked $\mathrm{WNW}$ of the epicenter, the former by about $10 \mathrm{~km}$ and the latter by perhaps no more than $2-3 \mathrm{~km}$, both are consistent with the notion of oblique slip at depth.

A third, relatively equivocal example of aseismic uplift preceding a subsequently recognized earthquake in southern California is that which may have preceded the $\mathrm{M}_{\mathrm{W}} 5.9$ Whittier Narrows earthquake of 1987. While it seems likely that there was indeed a degree of preseismic differential uplift within the epicentral region of this shock, persisting questions remain regarding its magnitude and form, both of which are related to uncertainties in rod (and, perhaps, other) error(s) in the 1975 and 1986 preseismic profile levelings (less accurate than 3rd-order) carried out by the Los Angeles County Road Department (Lin and Stein, 1989). These errors were certainly large, but where the errors in one set of rods (those used in the 1975 survey) can be corrected with some confidence, the rod corrections applied to those used in the 1986 survey remain in doubt. Other confusing issues are: (1) the magnitude of any subsidence associated with operations in the Montebello and Santa Fe Springs oil fields; and (2) the existence of an unexplained, abruptly defined subsidence trough between the Montebello and Santa Fe Springs fields, a feature that cannot be easily dismissed as measurement error (Lin and Stein, 1989, p. 96299631). Comparisons of repeated levelings along the north-south control line--which are probably the most revealing indices of deformation during the intervals of concern (1975-1986 and 1986-1987), since this line is roughly orthogonal to the strike of the presumed seismogenic fault plane (Shaw and 
Shearer, 1999)--produce perplexing results, whether one uses either the observed or corrected data (Lin and Stein, 1989, p. 9628). Based on the corrected data, and granting the persuasiveness of the argument advanced by Lin and Stein (1989, p. 9629) in support of the reality of what they call the "Pico Rivera hole", there is at least some possibility of a $0.1-\mathrm{ft}(0.0305-\mathrm{m})$ blunder in the 1986 leveling between two marks about $20-22 \mathrm{~km}$ from the starting point of the north-south control line as projected on a N-S azimuth. The removal of this postulated blunder would eliminate the abrupt definition of the northern boundary of the "Pico Rivera hole." Alternatively, the uplift "doublet" that appears in the 1975-1986 comparison may have resulted from either successive aseismic slip events on the Puente Hills fault or movement on two separate faults. The dimensions of the preseismic deformation field seem to be of the order of $30-35 \mathrm{~km}$; the preseismic differential uplift near the epicenter may have been as great as $40-50 \mathrm{~mm}$. Both of these generalizations, however, are clearly questionable.

Finally, we hesitate to dismiss this subject without mentioning two other aseismic events that preceded (but were not necessarily linked to) subsequent nearby earthquakes. These two examples share a common consideration: the observations that permitted their detection were confined to the footwalls of the identified seismogenic faults. The first, and probably most widely cited of such events, is the uplift that preceded the 1964 Niigata earthquake in Japan (Tsubokawa and others, (1968). Because recognition of the localized uplift, which peaked at about $50 \mathrm{~mm}$, was confined to the footwall, it is reasonably interpreted, as Thatcher (1976, p. 695) pointed out, as a second-order effect associated with downwarping of the footwall block. The second event consists of tectonic subsidence of the order of $0.3-0.4 \mathrm{~m}$ in the footwall block of the White Wolf fault during the period 1926-1931 (Castle and Elliott, 1982, p. 7002-7003, 7011; Castle and Yerkes, 1983, p. 36-39; Castle and others, 1987, p. 64-67). While the geodetic control that led to the detection of this subsidence is generously characterized as sparse, its apparently sharp definition invites speculation that it was precursive to the $1952, \mathrm{M}_{\mathrm{W}} 7.5$ Kern County earthquake. The occurrence of this earthquake more than 20 years after the indicated tectonic subsidence challenges belief in any association between the two events. Nevertheless, if there is in fact some correlation between the time delay following the onset of an aseismic deformational event and the magnitude of the the resultant earthquake, the described deformation and the 1952 earthquake may be mechanically related in some as yet obscure way.

\section{Conclusion}

Recognition of the differential uplift that preceded the 1994 Northridge earthquake is especially valuable, in our judgment, as an example of the type of localized deformational anomaly that can be expected to be disclosed and defined with the deployment of a well designed, dense array of continuously recording GPS receivers in southern California. Most of the uncertainties that are described in our reconstruction of this event, especially in the temporal domain, will largely disappear with the anticipated installation of this network.

Secondly, the recognition of this event, its dimensions and its probable duration, together with what we have learned from the detection of still other localized aseismic anomalies preceding earthquakes in southern California, suggests that a viable earthquake warning system may be closer at hand than any of us could have anticipated a decade ago. Continuous GPS observations should be capable of not only identifying anomalous deformational zones potentially vulnerable to near-term seismic activity, but might also provide some indication of what the magnitude of any postulated seismic event would be were it to occur at any given time in the history of the evolving anomaly--provided that it can be independently established that the duration of the anomalous event could be (or should be) related to the magnitude of any resultant earthquake. 


\section{Acknowledgments}

We are especially indebted to Kathy Koepsell of the National Geodetic Survey for her generous assistance in the acquisition of the survey data utilized in this report. Edward Riddle, Los Angeles County Surveyor, provided both advice and assistance in searching the geodetic record in the epicentral region of the Whittier Narrows earthquake. The illustrations were prepared by John K. Nakata. We also thank James C. Savage and Arthur F. McGarr for their meticulous and constructive reviews of earlier versions of this report.

\section{References}

Burford, R.O., and Gilmore, T.D., 1984, Vertical crustal movements in southern California, 19741978: U.S. Geological Survey Circular 905, 22 p.

California State Water Rights Board, 1962, The City of Los Angeles vs. City of San Fernando: California State Water Rights Board, Report of Referee no. 650079, v. II, various pages.

Castle, R.O., Alt, J.N., Savage, J.C., and Balazs, E.I., 1974, Elevation changes preceding the San Fernando Earthquake of February 9, 1971: Geology, v. 2, p. 61-66.

Castle, R.O. and Bernknopf, R.L., 1996, The southern California uplift and associated earthquakes: Geophysical Research Letters, v. 23, p. 3011-3014.

Castle, R.O., Church, J.P., Elliott, M.R., and Savage, J.C.,1977, Preseismic and coseismic elevation changes in the epicentral region of the Point Mugu earthquake of February 21, 1973: Bulletin of the Seismological Society of America, v. 67, p. $219-231$.

Castle, R.O. and Elliott, M.R., 1982, The sea slope problem revisited: Journal of Geophysical Research, v. 87, p. 6989-7024.

Castle, R.O., Elliott, M.R., Church, J.P., and Wood, S.H., 1984, The evolution of the southern California uplift, 1955 through 1976: U.S. Geological Survey Professional Paper 1342, 136 p.

Castle, R.O., Elliott, M.R., and Gilmore, T.D., 1987, An early-20th-century uplift in southern California: U.S. Geological Survey Professional Paper 1362, 70 p.

Castle, R.O. and Gilmore, T.D., 1992, A revised configuration of the southern California uplift: Geological Society of America Bulletin, v. 104, p. 1577-1591.
Castle, R.O. and Gilmore, T.D.,1994, The selective salvation of Zeiss Ni 1 levelings: U.S. Geological Survey Open-File Report 94-698, 29 p.

Castle, R.O., Gilmore, T.D., Mark, R.K., and Shaw, R.H., 1985, Empirical estimates of cumulative refraction errors associated with procedurally constrained levelings based on the GaithersburgTucson refraction tests of the National Geodetic Survey: Geophysical Research Letters, v. 12, p. 239-242.

Castle, R.O., Mark, R.K. and Shaw, R.H., 1994, An empirical assessment of refraction error in leveling as a function of survey order and environment: U.S. Geological Survey Bulletin 2114, 50 p.

Castle, R.O. and Yerkes, R.F., 1983, Historical surface deformation near Oildale, California: U.S. Geological Survey Professional Paper 1245, $42 \mathrm{p}$.

Craymer, M.R., Vanicek, Petr, and Castle, R.O., 1995, Estimation of rod scale errors in geodetic leveling, Journal of Geophysical Research, v. 100, p. $15,129-15,146$.

Federal Geodetic Control Committee, 1984, Standards and specifications for geodetic control networks: National Geodetic Information Branch, NOAA, Silver Spring, MD, various pages.

Freund, L.B. and Barnett, D.M., 1976, A twodimensional analysis of surface deformation due to dip-slip faulting: Bulletin of the Seismological Society of America, v. 66, p. 667-675.

Geller, R.J., 1997, Earthquake prediction: are further efforts warranted?: Geophysical Journal International, v. 131 , p. $425-450$.

Hauksson, Egill, Jones, L.M., and Hutton, Kate, 1995, The 1994 Northridge earthquake sequence in California: seismological and tectonic aspects: Journal of Geophysical Research, v. 100, p. $12,335-12,355$.

Hicks, S.D. and Crosby, J.E., 1974, Trends and variability of mean sea level 1893-1972: National Oceanic and Atmospheric Administration Technical Memorandum NOS 13, 14 p.

Hicks, S.D., and Shofnos, William, 1965, Yearly sea level variations for the United States: American Society of Civil Engineers, Proceedings, Hydraulics Division Journal, v. 91, n. 5, p. 23-32.

Hodgkinson, K.M., Stein, R.S., Hudnut, K.W., Satalich, Jay, and Richards, J.H., 1996, Damage and restoration of geodetic infrastructure caused by the 1994 Northridge, California, earthquake: U.S. Geological Survey Open-File Report 96-517, $70 \mathrm{p}$. 
Holdahl, S.R., 1982, Recomputation of vertical crustal motions near Palmdale, California, 19591975: Journal of Geophysical Research, v. 87, p. 9374-9388.

Holdahl, S.R., Strange, W.E., and Harris R.V. 1987, Empirical calibration of Zeiss Ni-1 level instruments to account for magnetic errors: Manuscripta Geodetica, v. 12, p. 28-39.

Jackson, D.D., Lee, W.B., and Liu Chi-Ching, 1980, Aseismic uplift in southern California: An alternative interpretation: Science, v. 210, p. 534536.

Lin, Jian and Stein, R.S., 1989, Coseismic folding, earthquake recurrence, and the 1987 source mechanism at Whittier Narrows, Los Angeles basin, California: Journal of Geophysical Research, v. 94, p. 9614-9632.

Mark, R.K., Gilmore,T.D., and Castle, R.O., 1987, Evidence of suppression of the unequal refraction error in geodetic leveling: Journal of Geophysical Research, v. 92, p. 2767-2790.

Mark, R.K., Tinsley, J. C., III, Newman, E.B., Gilmore, T.D., and Castle, R.O., 1981, An assessment of the accuracy of the geodetic measurements that define the southern California uplift: Journal of Geophysical Research, v. 86, p. 2783-2808.

Reilinger, R.E. and Brown, L.D., 1981, Neotectonic deformation, near-surface movements and systematic errors in U. S. releveling measurements: implications for earthquake prediction, in Simpson, D.W. and Richards, P.G., eds., Earthquake prediction, an international review (Maurice Ewing Series, v. 4): Washington, American Geophysical Union, p. 422-440.

Savage, J.C. and Hastie, L.M., 1966, Surface deformation associated with dip-slip faulting: Journal of Geophysical Research, v. 71, p. 48974904.

Schomaker, M.C., and Berry, R.M., 1981, Geodetic leveling: NOAA Manual NOS NGS 3, National Oceanic and Atmospheric Administration, Washington, (1-1)-(5-27) $\mathrm{p}$.

Shaw, J.H. and Shearer, P.M., 1999, An elusive blind-thrust fault beneath metropolitan Los Angles: Science, v. 283, p. 1516-1518.
Stein, R. S., 1981, Discrimination of tectonic displacement from slope-dependent errors in geodetic leveling from southern California, 19531979, in Simpson, D.W. and Richards, P.G., eds., Earthquake prediction, an international review (Maurice Ewing Series, v. 4): Washington, American Geophysical Union, p. 441-456.

Stein, R.S., Whalen, C.T., Holdahl, S. R., Strange, W.E., and Thatcher, W.R., 1986, SaugusPalmdale, California field test for refraction error in historical leveling surveys: Journal of Geophysical Research, v. 86. p. 9031-9044.

Steirman, D.J., and Ellsworth, W.L., 1976, Aftershocks of the February 21, 1973 Point Mugu, California earthquake: Bulletin of the Seismological Society of American, v. 66, p. 19311952.

Strange, W.E., 1981, The impact of refraction correction on leveling interpretations in southern California: Journal of Geophysical Research, v. 86, p. $2809-2824$.

Thatcher, W.R., 1976, Episodic strain accumulation in southern California: Science, v. 194, p. 691-695. 1999, New strategy needed in earthquake, volcano monitoring: EOS, Transactions of the American Geophysical Union, v. 80, p. 330-331.

Thio, Hong Kie and Kanamori, Hiroo, 1994, Source complexity of the 1994 Northridge earthquake and its relation to aftershock mechanisms in Ta-Liang and Keiti Aki, eds., Special issue on the Northridge California earthquake of January 17, 1994: Bulletin of the Seismological Society of America, v. 86, n. 1, pt. B, p. S84-S92.

Tsubokawa, I., Dambora, T., and Okada, A., 1968, Crustal movements before and after the Niigata earthquake in Kawasumi, H.,. General Report on the Niigata earthquake of 1964: Tokyo Electrical Engineering College Press, Tokyo, p. 129-139.

Yerkes, R. F. and Campbell, R.H., 1980, Geological map of east-central Santa Monica Mountains, Los Angeles County, California: U.S. Geological Survey Miscellaneous Investigation series Map I-1146. 